\title{
Humanidades: o lado humano da ciência
}

\author{
Antônio Carlos dos Santos \\ Doutor em Filosofia pela Université de Paris X, Nanterre, \\ Professor da Universidade Federal de Sergipe, \\ São Cristovão, Sergipe, Brasil \\ acsantos12@uol.com.br
}

\begin{abstract}
Resumo Dois são os objetivos deste texto. Primeiro, analisar as bases filosóficas das Humanidades na produção do saber e, de modo particular, na ciência. Segundo, refletir sobre a chamada "ciências humanas" enquanto parte do processo de desenvolvimento de uma nação. Discutir sobre o lado humano da ciência é um tema importante, urgente e necessário. No fim e ao cabo, e esta é nossa tese aqui, só há progresso e, sobretudo, só há desenvolvimento científico e tecnológico, se houver desenvolvimento humano. Isto significa dizer que o desenvolvimento de um país não pode prescindir das $\mathrm{Hu}-$ manidades.
\end{abstract}

Palavras-chave: conhecimento, ciências, humanidades, educação interdisciplinar.

\section{A base filosófica das Humanidades}

$\mathrm{D}$ o ponto de vista histórico, as Humanidades têm origem no estudo do latim e do grego. Embora esses estudos tivessem ganhado relevo no chamado humanismo do quattrocento italiano, eles não passavam de um cultivo daquelas línguas. O humanista do Renascimento era uma espécie de summa enciclopédica dos estudos humanos: conhecia, além das línguas clássicas, a chamada ciência natural, crônicas, textos e comédias do período, que hoje se diz literatura, sem considerar os conhecimentos das "ciências duras". Ou seja, o humanista era um profundo conhecedor de muito mais do que se chama humanidades, uma vez que não se reduzia a esses conhecimentos. Grosso modo, as Humanidades compõem as disciplinas que contribuem para formação (bildung) do homem, sem necessariamente haver uma utilidade prática. Isso significa dizer, segundo Rouanet (2003, p. 90),

que não tenham necessariamente como objetivo transmitir um saber científico ou uma competência prática, mas estruturar uma personalidade segundo certa paidea, vale dizer, um ideal civilizatório e uma normatividade inscrita na tradição, ou simplesmente proporcionar um prazer lúdico.

As Humanidades, no mundo contemporâneo, são as línguas e culturas clássicas, principais línguas estrangeiras e respectivas literaturas, além da história, da filosofia e das belas-artes. ${ }^{1}$ Num sentido mais lato do termo, englobam também as ciências sociais e aplicadas, tais como a geografia, a psicologia, o serviço social, entre outros.

1. Essa divisão é bastante controversa. Renato Janine Ribeiro, por exemplo, apresenta outra perspectiva. Ver: Ribeiro (2001, p. 35). Em outro registro, Ivan Domingues considera que a estruturação das chamadas ciências humanas foi muitíssimo longa, constituindo-se de 
Nas origens das Humanidades, primeiramente estão as línguas greco-romanas. A base delas, como é de conhecimento de todos, era o currículo mínimo: o trivium (gramática, retórica e dialética) e o quadrivium (aritmética, geometria, música e astronomia). Isso significa dizer que o aluno, ao estudar a gramática ou as línguas greco-romanas, entra em contato com toda a civilização ocidental, que é mobilizada com sua história, suas conquistas e derrotas, e sua capacidade de reinventar esse mesmo mundo. Ao voltar ao passado por meio das origens de nossa língua, o aluno faz, inexoravelmente, um paralelo com nosso tempo e provoca uma reflexão que lhe é pertinente e que lhe diz respeito.

Neste sentido, vale lembrar a razão pela qual o português, como disciplina do ensino médio, foi substituído pela comunicação e expressão durante o regime autoritário que vigorou no Brasil entre 1964 e 1985: o aprendizado da língua mater, transmitido segundo certas regras e padrões, foi substituído pela ideologia de que o importante é saber comunicar-se, exprimir-se, mesmo de forma errônea. Ora, nessa substituição, pouca gente deu-se conta de que o pano de fundo dessa substituição é que houve o esvaziamento do pensamento por uma pedagogia da facilidade. Ainda hoje corre solta essa visão de que não se pode exigir de uma criança uma normatividade linguística. Essa concepção nefasta esconde outra ainda pior: a da linguagem como meio de um pensamento crítico. Isto significa dizer que não é apenas a regra gramatical que conta, por exemplo, no aprendizado de uma língua, e sim a estrutura na organização das ideias, do pensamento, da visão crítica de si, do outro e do mundo. Manter o aluno no seu gueto linguístico é uma boa forma de marginalizá-lo, de excluí-lo do acesso aos bens culturais, à participação política, à cidadania (Rouanet, 2003, p. 92).

O regime autoritário acabou, mas não a dominação e o controle das massas por parte daqueles que detêm o poder econômico. Ora, como a língua portuguesa é fruto material das línguas greco-romanas, que faz parte de nossa identidade cultural, e que ela será ainda mais robusta se tivermos a capacidade de preservarmos nossas tradições, voltarmos a ela com toda força e agressividade é o modo que temos de evitar o risco de sua desconfiguração, sobretudo em épocas de tanto estrangeirismos e consequentemente de um empobrecimento cultural da própria língua mater.

Em segundo lugar, estão as línguas estrangeiras. De modo particular, o francês e o inglês foram as lín- guas mais dominantes no Brasil e, mais recentemente, o espanhol, que vem se fazendo presente cada vez mais. No que diz respeito ao francês, três momentos são marcantes na cultura brasileira: o primeiro, ainda no século XVIII, quando os enciclopedistas chegaram aqui por meio dos inconfidentes mineiros e instigaram a insurreição; a segunda, no século XIX, quando a cultura francesa dominava a elite como modo de vida culta e sofisticada. Naquele momento, Paris passava a ser o farol civilizatório no início do mundo contemporâneo: da cozinha ao traçado das ruas, das ideias triviais ao movimento feminista, das músicas românticas aos cabarés, todo o mundo se rendia aos encantos da cultura francesa. Finalmente, após a Segunda Guerra Mundial, a França entrou num declive cultural sem precedentes nos trópicos e o império americano instalou-se não somente como força militar, mas, sobretudo, como poder político-cultural. Ora, talvez nesse aspecto a presença francesa no mundo tenha reduzido suas atividades, concentrando-se mais no campo da filosofia e das ciências humanas (Rouanet, 2003, p. 95). Quem, na segunda parte do século XX, não leu algum texto dos estruturalistas, como Lévi-Strauss, Althusser, ou dos existencialistas, como Sartre e Simone de Beauvoir? Quem não foi influenciado, de algum modo, pelas ideias dos pós-estruturalistas, como Foucault, Derrida, Deleuze ou Castoriadis? Como negar que todo esse aparato crítico que se espalhou pelo mundo teria arrefecido suas armas? Por que há uma insistência parruda em afirmar que a cultura francesa entrou em decadência?

O curioso é que a obrigatoriedade do ensino de francês no Brasil chegou exatamente durante o regime autoritário, que via nesse ensino uma cultura em franco declínio, quase morta. No seu lugar, instalar-se-ia a anglo-saxônica, que apontava para um ensino técnico, eficiente, mais próxima das necessidades daquele momento histórico. Se com o francês aprender-se-ia a cultura, com o inglês, falar-se-ia esse idioma em função de melhor servir ao desenvolvimentismo daquela época. É verdade que não podemos reduzir a língua inglesa à tecnocracia e a francesa, à humanidade. O fato é que a francesa é vetor de cultura, diferentemente da inglesa, que não apresenta essa vocação quase natural da cultura europeia.

Seja como for, o fato é que o francês passou a ser visto como ultrapassado e o inglês, como idioma da modernidade, da utilidade, da sociedade pragmatista do consumo. Não haveria mal nenhum em a cultura brasileira assimilar elementos de uma outra, como a

quatro fases bem distintas, que ele chama de "arqueologia das ciências humanas": 1) a idade cosmológica, na antiguidade clássica, época em que o problema do homem é pensado a partir do cosmos; 2) a idade teológica, no período medieval, quando o problema do homem é pensado a partir dos desígnios da providência divina; 3) a idade mecânica, na modernidade, época em que o homem adquire autonomia e é interrogado a partir dele mesmo e das condições da subjetividade; 4) a idade da história, na passagem da modernidade para os dias atuais, quando temos um desconcentramento do homem e a dissolução da natureza humana nas positividades da história e da cultura. Para maiores detalhes, ver: Domingues (1999). 
americana, mas o problema maior é que adoção do inglês como língua obrigatória acarretou a aniquilação do francês. Ou seja, de possíveis poliglotas, passamos a monoglotas, uma vez que não tínhamos como escolher: a consequência maior foi o enfraquecimento da diversidade cultural do país, já fragilizado pela ditadura, esvaziando-se ainda mais os conteúdos humanos.

A presença da cultura espanhola pelo mundo começou com os reis católicos Fernando e Izabel, que visavam uma política de nacionalização, sobretudo após a expulsão de árabes e judeus da Península Ibérica. É verdade que o impulso necessário à dominação do espanhol pelo mundo se deu a partir de 1492, com as grandes navegações e descobertas na América, mas não deixa de ser menos verdade que a hegemonia espanhola ganha fôlego no século XX com o general Franco, que proíbe outras línguas no território espanhol, a exemplo do catalão e do galego.

No Brasil, o espanhol foi introduzido em 1919, com a institucionalização dessa disciplina no Colégio Pedro II, pelo professor Antenor Nascentes, em caráter optativo. Em 1942, o governo Getúlio Vargas determinou a substituição do alemão pelo espanhol, motivado não só pelo fato de o alemão ser a língua do inimigo na Segunda Guerra Mundial, mas também como uma tentativa de sufocar as colônias alemãs no sul do país, que insistiam em manter a língua dos seus antepassados, que resistiam em adotar o português como língua local. Enfim, o espanhol foi justificado no ensino médio, inclusive constitucionalmente, em virtude da integração econômica, social, política e cultural dos povos da América Latina. A prática denuncia que há ensino, sim, do espanhol, mas não há, infelizmente, uma difusão da cultura espanhola, como um bem cultural (Lisboa, 2009, p. 205).

Em terceiro lugar, o ensino da história tem fortes laços com as Humanidades. Tradicionalmente, a história está vinculada a fins cívicos e patrióticos. Estuda-se história para seguir bons exemplos e, sobretudo, aguçar a imaginação. Quem já não se viu em Roma, lutando no seu exército? Quem nunca se emocionou com as histórias de Rômulo e Remo? E as histórias de João e Maria? Essa história poderia não ser científica, mas estimula os sonhos que impulsiona o leitor à ação, e, por isso mesmo, faz dele alguém que constrói a própria história. Por trás daquelas histórias aparentemente ingênuas, poder-se-ia extrair alguma inspiração democrática: por trás do herói, ou até mesmo do super-herói, sempre tem o humano. Assim, ao ler sobre a Revolução Francesa, por exemplo, o leitor treina "o espírito para o hábito do pensamento retrospectivo e prospectivo, como memória e antecipação, recaptura do passado e vivencia do presente como história, isto é, um presente plástico, maleável, habitado por um futuro que depende de nós con- cretizar" (Rouanet, 2003, p. 96). Ou seja, essa história estimula o pensamento e a imaginação e nos impulsiona a transformar a realidade como elemento histórico.

Ora, o que ocorreu no Brasil, especialmente durante o regime militar? A história passou a ser desinteressante. No lugar da interpretação dos fatos, apenas os próprios fatos eram suficientes: não era preciso ir além deles, pois a interpretação não era bem-vista. A história deixou de ser discussão sobre o passado para ser uma sucessão de datas, nomes e lugares, especialmente os grandes feitos. A história factual ou quantitativista passou a imperar no Brasil porque servia bem aos propósitos do regime, fundamentada nos manuais positivistas. Apesar dessa situação plasmada no ensino em todos os níveis, no Brasil sempre houve formas de romper os grilhões da censura, da opressão militar, da ditadura ideológica. Afinal, como não relacionar a história romana de Gibbon com a nossa situação política? Como não se situar politicamente ou sensibilizar-se com as injustiças ao ler a primeira parte de O Capital de Marx? Como não se emocionar ao ler sobre a Queda da Bastille, na festa nacional francesa? Ora, esses fatos históricos são mero pretexto para provocar uma reflexão política. Aprendemos com a história a bravura de um Alexandre e a humanidade de um Gandhi: com eles, tornamo-nos mais humanos, conscientes de sua força e de seus limites.

Em quarto lugar, a filosofia, que está no coração das Humanidades. É difícil estudar qualquer área do conhecimento humano que não passe necessariamente pela filosofia, porque as bases do pensamento ocidental estão fincadas nela. Afinal, como estudar a psique humana sem estudar o mito grego? Como estudar a sociologia sem conhecer as bases da cidade antiga, plasmada na República de Platão? Como pensar a política sem estudar Maquiavel, Montesquieu, Merleau-Ponty? Por essa razão, a filosofia é a atividade do pensamento enquanto tal, e, por isso mesmo, é universal, distanciando-se da ciência, que é sempre particular e tem um objeto próprio. Já a filosofia tem como corpus uma tradição, que apresenta grande lastro cultural.

Quando estudamos filosofia, não aprendemos apenas sobre o pensamento de determinado filósofo ou corrente filosófica: aprendemos a experiência da razão e da linguagem no seu tempo histórico, em que o pensamento busca pensar-se a si mesmo, falar de si mesmo e dos valores (o bem, o verdadeiro, o belo, o justo). Essa experiência, concretizada no e pelo trabalho de cada filósofo, constitui o lastro da tradição, que no fundo dá origem ao discurso filosófico. Por essa razão, a filosofia faz parte da educação, entendida como formação. Como afirma Chaú (2009, p. 10), "como interesse pelo trabalho do pensamento e da sensibilidade, como desenvolvimento da refle- 
xão para compreender o presente e o passado, e como estímulo à curiosidade e à admiração, que levam à descoberta do novo".

A filosofia, como atividade do pensamento, como pensamento crítico, não combina com regimes autoritários, e por isso foi extinta no Brasil entre 1964 e 1980. No seu lugar, como todos sabem, foi colocada a disciplina Educação Moral e Cívica, inicialmente ministrada por militares, cujo objetivo era a doutrinação patriótica e a recusa da insurreição da razão de Estado. Mas o efeito mais nocivo não foi esse, e sim a reforma educacional após o AI-5, quando foi dada enorme importância aos conhecimentos técnico-científicos e desprezadas as Humanidades, sob a alegação de que elas não condiziam com o momento desenvolvimentista do país naquele momento.

Ainda, como registra Chauí (2009, p. 9-10),

o Ensino Médio passou a ser visto de maneira puramente instrumental (e não mais como um período formador), isto é, como etapa preparatória para a universidade e esta, como garantia de ascensão social para uma classe média que, desprovida de poder econômico e político, dava sustentação ideológica à ditadura e precisava ser recompensada. Para isso, teve início o ensino de massa, sob a alegação de democratizar a escola. O modelo educacional submeteu o ensino às condições do mercado, isto é, tomou a educação como mercadoria, [...] ao estimular a privatização do ensino e minimizar a presença do Estado do campo da educação, tornando precária e insignificante a escola pública e fomentando a exclusão social.

A volta da filosofia aos bancos escolares pode provocar, assim, o debate em torno do qual o pensamento reflexivo é o centro da cultura e, a partir dele, disseminar alguma ilustração num espaço tão marcadamente tecnocrata.

Neste sentido, as Humanidades podem representar o contrapeso à tecnocracia, exatamente num momento em que o Brasil parece ganhar espaços econômicos internacionais. Mas longe de apresentar qualquer hostilidade às ciências empíricas, uma vez que elas podem conviver perfeitamente bem. O que se deve evitar é a tendência, como se fosse natural, de "pensar tecnicamente problemas que não são técnicos" (Rouanet, 2003, p. 100). Isso significa dizer que muitos problemas técnicos não podem ser resolvidos pura e simplesmente pelo olhar técnico: o olhar das Humanidades pode ser um excelente sopro de vida num espaço anti-humano. Pressupõe ir além das lunetas tecno-científicas. É preciso pensar o homem contemporâneo que não está mais voltado para a alta especialização, mas que, ao contrário, busca estabelecer inter-relação com as várias áreas do saber, como a interdisciplinaridade no mundo contemporâneo, por exemplo, que é uma tentativa de responder a alguns equívocos do mundo moderno, ${ }^{2}$ à medida que tenta evitar a fragmentação exacerbada do conhecimento. Assim, uma boa formação humanista, num terreno interdisciplinar, prepara muito mais do que uma alta educação profissionalizante.

Tendo o olhar crítico dessas áreas do saber, o cultivo das Humanidades pode contribuir para a formação política, num mundo que tende a achar que tudo é natural. Com isso, a ideia de que as contradições da sociedade são frutos da cultura humana, produto da história, fica fortemente enfraquecida. Como afirma Rouanet (2003, p. 100),

ninguém pode sustentar essas pueridades depois de ter lido Marx e Freud: Marx, que mostrou como a cultura se enraíza num contexto de exploração social, e Freud, que mostrou que ela é sofrimento sublimado, e se destina a tornar suportáveis os sacrifícios pulsionais exigidos por uma sociedade injusta. Longe de ser um Parnaso elevando-se acima das nuvens, a cultura está umbilicalmente ligada ao mundo do trabalho e à violência de classe - é o outro lado de uma sociedade regida pelo valor de troca e pelo princípio da utilidade.

É verdade que nada garante que um humanista seja absolutamente consciente de seu papel crítico e de agente da história e que eventualmente um nazista também não tenha alta formação humanista. Ou seja, não há relação necessária entre humanista moralmente bom e nazista forçosamente "ruim": o campo da cultura é vasto e por isso há espaço para a produção do seu reverso, ou seja, a barbárie. No entanto, quanto mais aberto e diversificado for o debate tanto maior serão as investidas contra o obscurantismo.

Enfim, mesmo que as Humanidades não servissem para nada, ao menos serviriam para o puro prazer. Esse prazer é desinteressado, não tem, portanto, utilidade alguma. Ele visa pura e simplesmente o deleite dos sentidos, da harmonia dos sons linguísticos, da estrutura estilística ou estética, da história narrada ou simplesmente inventada que nos emociona. Isso, por si só, já é suficiente para nos prender a atenção e nos tornar uma pessoa melhor. Por essa razão, as Humanidades precisam, mais do que nunca, ser fortificadas e revitalizadas. Dar ênfase ao debate, à pesquisa séria, envolvendo várias áreas do saber, provocando a reflexão crítica da realidade, entre outras atividades, a fim de compreender melhor o lugar do homem no

2. Como registra Domingues (1999, p. 32), referindo-se ao mundo moderno: "Teatro de uma revolução científica sem par na história da humanidade, os tempos modernos são também a época em que se instala uma nova forma de conhecimento do homem, agora em torno da ciência e não mais da filosofia ou da teologia racional". 
mundo contemporâneo. É assim que as Humanidades podem ajudar no processo de desenvolvimento pelo qual está passando o Brasil.

\section{As Humanidades como parte do processo de desenvolvimento de uma nação}

Uma das maiores características da ciência é o seu poder de atualizar-se à medida que é capaz de formular antigas questões de maneira inovadora. Se é verdade que até bem pouco tempo atrás, por exemplo, muitos economistas pensavam que o país precisava crescer de maneira "milagrosa", ou seja, de forma rápida e avassaladora, para compensar seu atraso econômico e social, hoje poucos adeririam a essa receita. Se o fim último desse desenvolvimento era nobre, pouco se questionava sobre os seus meios e, por isso, estar-se-ia justificado o domínio da natureza e a sua exploração de forma extremada, apontando para uma espécie de um genocídio generalizado, a que muitos atribuíram o nome de progresso. É hora de perguntarmos: que tipo de desenvolvimento? A que preço? Qual a relação custo-benefício? Vamos cometer os mesmos erros da época autoritária desenvolvimentista? Como podemos nos organizar política e ideologicamente em torno de um pensamento autônomo? Isso seria possível? De que forma? Em todas essas questões tem a mão das Humanidades e elas podem e devem ajudar o Brasil a pensá-las. Isso porque só poderá haver desenvolvimento científico com desenvolvimento humano, sob pena de essa fase se tornar, mais uma vez, desenvolvimentista e predatória.

Tradicionalmente, os ambientalistas e estudiosos da natureza veem Bacon e Descartes como os mentores intelectuais da apropriação humana da natureza por meio do desenvolvimento técnico. ${ }^{3}$ Com o fito de tornar a vida humana melhor na Terra, eles divulgaram uma ideia, cada vez mais corrente no mundo contemporâneo, de forma anacrônica: a chamada "qualidade de vida". Para eles, não bastava viver, era preciso viver bem e essa visão passava necessariamente por uma nova percepção do lugar do homem no mundo, de forma menos contemplativa e mais ativa, para lembrarmo-nos da bela expressão de Hannah Arendt (1991). No projeto científico que os dois pensaram, de forma distinta e por meios diversos, ambos se preocuparam com o caráter moral do desenvolvimento científico. Não foi à toa que Bacon pensou a Casa de Salomão, na Nova Atlântida, como uma casa de discussão e disseminação da ciência em que tudo passava pelas mãos dos cientistas. $\mathrm{O}$ mesmo ocorreu com Descartes, que, na sua obra Princípios da Filosofia, pensou a "árvore do conhecimento", em que as raízes eram a metafísica; o tronco, a física; os ramos, a mecânica e a medicina; e o seu coroamento, a moral. Aliás, já no início do Discurso sobre o método, Descartes afirma que não é suficiente ter o espírito bom, porque o principal é saber aplicá-lo bem. Ou seja, os dois filósofos deram extrema importância aos riscos implicados no desenvolvimento técnico-científico, desde o nascedouro da ciência.

Essa questão, lamentavelmente, é quase sempre esquecida por aqueles mesmos teóricos que pregam uma espécie de retorno às cavernas ou uma separação completa entre o homem e a natureza. Ora, como já disse Rousseau, esse é um caminho sem volta. Não é possível mais viver em locais paradisíacos e intocáveis pelo mundo civilizado. A questão que às Humanidades se põe é: como conciliar desenvolvimento e avanço civilizatório? Que relação podemos estabelecer entre desenvolvimento e desastres naturais, históricos e humanos? Até quando a ciência vai desconsiderar a catástrofe de ausentar as Humanidades do debate sobre o desenvolvimento econômico?

As perguntas são imensas e suas respostas nem sempre estão a olhos vistos. Afinal, até onde vai dar a manipulação genética? A bioética está sendo considerada nos últimos avanços científicos vinculados a essa área do saber? Como ficam as questões ecológicas com a necessidade de novas energias alternativas à nuclear, especialmente com o crescimento econômico dos países emergentes? Como anda o problema das energias fósseis (seus limites, financiamentos, dificuldades de exploração, entre outros)? Quais as implicações dos alimentos transgênicos para a saúde humana? Com tantas questões abertas, ainda a serem respondidas, como as Humanidades podem calar-se? $\mathrm{Ou}$, dizendo de outra forma, como querer emudecê-las? Por essas e outras razões, elas incomodam a ciência ou os cientistas por fazer tais questões.

É verdade que, diante de problemas polêmicos como os alimentos transgênicos, por exemplo, há sempre aqueles que reduzem a questão à ideia de que as Humanidades entravam o desenvolvimento, dificultando a ciência de alimentar o povo faminto. $\mathrm{Ou}$, no caso da preservação das áreas verdes do Brasil, há sempre quem recorrerá à retórica, justificando que as Humanidades não querem o desenvolvimento. Isso tudo é mera simplificação e, por isso, por vezes o debate não avança, bloqueando os argumentos que podem apontar para uma melhor compreensão das questões entre o universal e o local, entre o eterno e o provisório, entre o avançado e o atrasado. Ora, nada mata mais a ciência do que a obsessão por uma suposta verdade, dada como absoluta, fruto do "ou 
tudo ou nada". Nada é mais perigoso para a ciência do que uma ideia política dogmática, com ares de assertivas progressistas, com a justificativa de que os estudos são embasados "cientificamente" em técnicas e procedimentos absolutamente inquestionáveis.

É por isso que as Humanidades desconfiam dessa visão supostamente certeira da ciência. Nunca é demais lembrar que as Humanidades têm heterogeneidade quanto ao objeto de pesquisa, apresentam divergência quanto aos interesses de suas análises, contêm uma variedade enorme de técnicas para melhor lidar com o humano, e multiplicam cada vez mais os tipos de saberes para melhor entender o homem na sua complexidade do mundo contemporâneo. ${ }^{4}$ Por que desconfiar da razão técnica e instrumental? Porque as Humanidades têm uma disposição maior à incoerência e à anarquia discursiva. Elas provocam uma reflexão entre os interlocutores sobre o lado humano do cientista. Elas interrogam sobre seus possíveis erros, acertos, falhas, lacunas, condutas e, sobretudo, sobre sua consciência. Não é por acaso, mais uma vez, que elas sofrem certa hostilidade da ciência. Trata-se de uma presença incômoda, que desconcerta seus pares pelas questões que lhe são feitas. Afinal, como bem mostrou Max Weber, no seu clássico Ciência e Política: duas vocações (1993), as Humanidades provocam um desencantamento da própria ciência, à medida que esta quer uma adesão acrítica de suas práticas e procedimentos; a aceitação tácita de uma ideia de progresso linear e contínuo rumo ao melhor; a compreensão imediata do tempo presente de forma equivocada, em que o tempo atual é melhor do que o passado atrasado e conservador; a convicção, sem reflexão, de que a racionalidade tecnológica na economia e na política é uma decisão técnica e, por isso, melhor para todos; a exaltação do mercado como sucedâneo da felicidade, com o abandono da reflexão do pensamento.

O lado mais visível do abandono da cultura humanística do mundo contemporâneo é a indústria cultural, em que tudo é subordinado ao mercado. Como registra Olgária Matos (2001, p. 115),

a assimilação dos valores do consumo e aquisição de bens materiais pela sociedade de massa constituem uma poderosa simplificação do dinamismo do pensamento, o que significa dissolução do conjunto do pensável e do possível na noção de 'necessidade' e 'inelutabidade' econômica, circunstância que de- grada a democracia em tecnocracia, tecnocracia que constrói e propaga como pressuposto a 'impossibilidade do possível'.

Isto significa dizer que, além de reduzir tudo à mera esfera do consumo, a indústria cultural esteriliza o pensamento de tal forma que não mais se acredita numa outra forma de viver, em que não é possível nem mesmo tentar mudar ou pensar o diferente. Há, na verdade, uma padronização dos hábitos, modos e sonhos coletivos, plasmado na finitude do tempo presente e na pouca crença de mudanças futuras.

Ainda segundo Matos (2001, p. 117), “a recaída da cultura no reino comercial e financeiro - e seu correlato, o mundo das mídias - cultura que se construiu contra eles - põe em risco as mais elevadas obras de pensamento: a arte, a literatura, a ciência e a filosofia". Isso porque as mídias padronizam comportamentos, veiculam estereótipos, promovem fanatismos, estimulam o consumo cego, transformando a facticidade em norma, em que o Estado perde sua centralidade e as mídias transformam-se num "Estado paralelo" (ou Terceiro Estado), que, no fundo, defende o Estado mínimo. Aqui, os cidadãos são reduzidos à condição de massa, dispensáveis e supérfluos, que, por serem incompetentes e terem fracassado na lógica do mercado, foram expulsos do paraíso consumista: são os desempregados que, como bem diz Marx, formam os "exércitos de reserva". Por essa razão, Adorno (1971) afirma "que a luta contra a cultura de massa só pode ser levada adiante se mostrada a conexão entre a cultura massificada e a persistência da desigualdade social". Ora, a percepção desse problema é fundamental para retomar o élan perdido historicamente: a mudança do quadro de exploração socioeconômica passa pelo papel das Humanidades no seio da sociedade.

É importante notar que a base da educação humanística é a formação, mas, na sociedade regida pelas mídias do mundo contemporâneo, ela vira performance. Não se exige mais o rigor científico e acadêmico ao longo do período de formativo, por vezes enfadonho, monótono, exaustivo. Para muitos, dispensar-se-ia o uso de método na pesquisa e nos trabalhos acadêmicos, afinal, trata-se de muito trabalho! Não é necessário tanto rigor na escrita científica, nas regras gramaticais, na ortografia. No mundo da indústria cultural, tudo é simplificado ao mínimo, ao

\footnotetext{
4. Muitos epistemólogos negam a cientificidade das ciências humanas. Foucault, por exemplo, na obra Triedo dos saberes (1999), elaborou uma divisão global das ciências humanas, definindo uma espécie de espaço epistemológico constituído por três eixos fundamentais da racionalidade do saber: $1^{\circ}$ ) o eixo da matemática e da física, protótipo de toda cientificidade; $2^{\circ}$ ) o eixo das ciências da vida, da produção e da linguagem, em que estão situadas a biologia, a economia e as ciências da linguagem; $3^{\circ}$ ) o eixo da reflexão filosófica. Esses eixos, unidos dois a dois, formam três planos: $1^{\circ}$ ) o das matemáticas aplicadas (matemática, ciências da vida, da produção e da linguagem); $2^{\circ}$ ) o da formalização do pensamento (eixo da matemática e da reflexão filosófica); $3^{\circ}$ ) o das ontologias regionais (comum ao eixo da ciências da vida, da produção e da linguagem). As ciências humanas não formariam nenhum eixo, mas sim uma "nuvem" de disciplinas, participando de modo diversificado, das três dimensões citadas acima.
} 
elementar, ao básico, para ser compreendido por um público que tem aversão à cultura e mostra hostilidade àquilo que ela chama de "cultura elitista". Por isso, não é preciso saber literatura ou as regras gramaticais da língua vernácula, basta aparentar saber. Afinal, o que mais irá contar é o gesto, é a performance do sujeito em evidência na mídia. Para que ele possa aparecer, ele precisa estar com o roteiro todo pronto, sem espaço para improvisação. Por isso, como registra Adorno (1985, p. 191),

desde Hamlet a vacilação (a dúvida) tem sido para os modernos um sinal do pensamento e da humanidade [...]. Hoje os indivíduos recebem do poder (midiático) seus tickets já prontos, assim como consumidores vão buscar seus automóveis nas concessionárias da fábrica.

Ou seja, não é preciso pensar, duvidar, questionar: basta comprar, aceitar tudo tacitamente e pronto. Ora, num mundo regido por essa lógica, como as Humanidades podem romper com este círculo e exercer sua função precípua que é pensar o rosto humano da ciência? Como elas podem ultrapassar a visão meramente estereotipada, vistas pelas outras ciências, para uma visão mais ativa e constituidora do desenvolvimento de um país?

Para concluir, sem muita resposta, o traço mais característico das Humanidades é que elas fazem parte da construção e do aprimoramento do homem como ser de cultura. Elas não visam o resultado científico cego, como o fazem as ciências exatas, por exemplo, que apresentam uma linguagem matemática unificadora, a-histórica e acrítica. As Humanidades não só visam resultados que se aproximam da verdade como buscam um sentido para a ação. Como bem registrou Michel Foucault, as Humanidades não receberam uma herança bem delineada e sua tarefa seria elaborar esses conceitos segundo aspectos científicos e metodologicamente constituídos. Ou seja, trata-se de um processo que, por incrível que pareça, é recentíssimo e ainda em construção, porque é complexo do ponto de vista metodológico. Nas palavras de Foucault (1999, p. 481),

o que explica a dificuldade das "ciências humanas", sua precariedade, sua incerteza como ciências, sua perigosa familiaridade com a filosofia, seu apoio mal definido sobre outros domínios do saber, seu caráter sempre secundário e derivado, como também sua pretensão universal, não é, como frequentemente se diz, a extrema densidade de seu objeto; não é o estatuto metafísico ou a indestrutível transcendência desse homem de que elas falam, mas, antes, a complexidade da configuração epistemológica em que se acham colocadas.

Talvez essa dificuldade metodológica influencie negativamente as outras ciências a aceitarem-nas como tais, ou seja, como não científicas, e por isso releguem-nas ao segundo plano no hall das áreas do conhecimento estratégicas para o país. Um bom exemplo disso é que no grande projeto do atual governo brasileiro, intitulado "Ciência sem Fronteira", que visa a promover o intercâmbio de estudantes e pesquisadores brasileiros no exterior, bem como atrair cientistas de ponta para o Brasil, não foi incluída nenhuma área das Humanidades. Afinal, as Humanidades não serviriam mesmo para grande coisa... Pensar assim é dar continuidade à velha política desenvolvimentista. Quando vamos compreender que só há desenvolvimento econômico de um país junto com o das pessoas?

\section{Referências}

ADORNO, Teodor W. Televisão, consciência e indústria cultural. In: COHN, Gabriel (Org.). Comunicação e indústria cultural. São Paulo: Editora Nacional, 1971.

_. Elementos do antissemitismo. In:

HORKHEIMER, Max. Dialética do esclarecimento. Rio de Janeiro: Jorge Zahar, 1985. p. 191.

ARENDT, Hannah. A condição humana. Rio de Janeiro: Forense Universitária, 1991.

CHAUÍ, Marilena. Prefácio. In: MARÇAL, Jairo (Org.). Antologia de textos filosóficos. Curitiba: SEED-PR, 2009.

O grau zero do conhecimento. 2. ed. São Paulo: Edições Loyola, 1999.

DOMINGUES, I. Disciplinaridade, multi, inter e transdisciplinaridade - onde estamos? Anais... 63 Reunião da SBPC, Goiânia, julho 2011.
FOUCAULT, Michel. As palavras e as coisas: uma arqueologia das ciências humanas. São Paulo: Martins Fontes, 1999. GOETHE. Fausto. Tradução de João Barrento. Lisboa: Relógio d'Água, 1999.

LEIS, H. R. Especificidades e desafios da interdisciplinaridade nas ciências humanas. In: PHILIPPI JÚNIOR, A.; SILVA NETO, A. (Orgs.). Interdisciplinaridade em ciência, tecnologia E inovação. Barueri: Manole, 2011.

LISBOA, Maria Fernanda Grosso. A obrigatoriedade do ensino de espanhol no Brasil: implicações e desdobramentos. Revista Sínteses, 2009.

POMBO, O. Interdisciplinaridade: conceito, problemas e perspectivas. In: POMBO, O. LEVY T \& GUIMARÃES, H. (Orgs.). A interdisciplinaridade: reflexões e experiências. Lisboa: Editora Texto, 1993. 
POMBO, O. Interdisciplinaridade: ambições e limites. Lisboa: Relógio d'Água, 2004.

RIBEIRO, R. J. Humanidades: um novo curso na USP. São Paulo: Edusp, 2001.

MATOS, Olgaria. As humanidades e sua crítica à razão abstrata. In: RIBEIRO, Renato Jeanine. Humanidades: um novo curso na USP. São Paulo: Edusp, 2001.
ROUANET, S. P. Reinventando as humanidades. Humanidades, 49, 2003.

SANTOS, Antonio Carlos; BECKER, Evaldo (Orgs.). Entre o homem e a natureza: abordagens teórico-metodológicas. Porto Alegre: Redes Editora, 2012.

WEBER, Max. Ciência e política: duas vocações. São Paulo: Cultrix, 1993.

\title{
Humanities: the human side of science
}

\begin{abstract}
The objective of this paper is twofold: First, to analyze the philosophical underpinnings of the humanities and the production of knowledge, particularly within science, and second, to envision the development of the so-called "Human Sciences" as a fundamental aspect of national development. The discussion of science within the realm of humanity is an important, urgent and necessary topic. Our thesis postulates that ultimately, progress, particularly scientific and technological development, can only occur when paralleled by human development. According to this, the development of a country cannot transpire without the humanities.
\end{abstract}

Key words: knowledge, humanities, science, education, interdisciplinary, philosophical underpinnings, nation.

\section{Humanidades: el lado humano de la ciencia}

\section{Resumen}

Dos son los objetivos de este trabajo. Primero, analizar las bases filosóficas de las humanidades en la producción del saber y, de modo particular, en la ciencia. Segundo, reflejar sobre el denominado "ciencias humanas" en cuanto parte del proceso de desarrollo de una nación. El discutir sobre el lado humano de la ciencia es un tema importante, urgente y necesario. Al fin y al cabo, y esta es nuestra tesis aquí, solo hay progreso, sobretodo, desarrollo científico y tecnológico, si hay desarrollo humano. Esto significa decir que el desarrollo de un país no puede prescindir de las humanidades.

Palabras claves: conocimiento, ciencias, humanidades, educación interdisciplinar.

Data de recebimento do artigo: 13/5/2013

Data de aprovação do artigo: 20/12/2013 